\title{
Strategic digital transformation of organisations
}

\author{
Antonina Lazić \\ Faculty of Organisational Sciences \\ University of Belgrade \\ Belgrade, Serbia \\ a.lazic@koridorisrbije.rs
}

\author{
Marija Jović \\ Faculty of Organisational Sciences \\ University of Belgrade \\ Belgrade, Serbia \\ marija.j@fon.bg.ac.rs
}

\begin{abstract}
The contemporary business setting, as well as the era of a more and more intensive digital development of society, are creating greater challenges for organisations when it comes to introducing digital processes into almost every domain of business, that is, conducting a digital transformation of the organisation. Conducting a strategic digital transformation of an organisation is becoming one of the key elements of its business success. This paper aims to analyse the key requirements regarding a strategic digital transformation, as well as to analyse those organisations which have successfully performed this process, and those who did not manage to reach the desired goals in the process of strategic digital transformations.
\end{abstract}

Keywords-digital transformation, organisations, strategic.

\section{INTRODUCTION}

Conducting a strategic digital transformation of organisations is becoming a more and more present practice in business strategies of organisations in the last couple of years. "For companies from various sectors of the economy, there is an opportunity to use digital technology, to transform their businesses, products, and services, and thus build their competing position on knowledge and innovation" [1]. Despite the numerous challenges that the organisations are facing during the implementation of the strategic digital transformation, they are developing an awareness of the importance and role that this form of a transformation has for the business and operating of organisations in the 21 st century, a century of technological innovations. "The new digital economy, as well as the economic activity coming from the online connection of billions of people, businesses, data, devices, and processes, has created extraordinary possibilities for individuals, companies, and countries to improve their competitive strategy thanks to the new technologies" [2].

Even though the development and improvement of information technologies happening in the last couple of decades have immensely contributed the successful business of companies, enterprises, and organisations in various domains, it is important to consider the numerous challenges which were present during the introduction of information technologies into various work processes. The question of whether a strategic digital transformation is always an adequate step for an organisation remains open. Authors [3] point out to certain risks which come with the digital transformation of organisations, such as the potential failure of tracking and measuring the results of the implementation of the digitally transformed processes, inadequately defined mission and goals of the organisation, failure during the defining of needs and values of clients, nonexistence of a complete plan for a new business strategy, etc.

This paper aims to analyse the key requirements regarding a strategic digital transformation, as well as to analyse those organisations which have successfully performed this process, and those who did not manage to reach the desired goals in the process of strategic digital transformation.

\section{STRATEGIC DIGITAL TRANSFORMATION OF ORGANISATIONS: KEY ELEMENTS}

Despite the existence of various definitions and different operationalizations of the term digital transformation of organisations, it is possible to say that the definition which is most widely accepted and most often used by numerous authors is the one defining digital transformation as a way of doing business which implies the application of strategies within which modern digital technologies are used so as to ensure a more efficient operating of organisations, performance of the employees, and a more successful relationship with the clients [4]. On the other hand, digital strategy is a concrete plan based on which the digitalisation of various processes in an organisation is conducted.

It is clear that on the modern market, which is extremely demanding, the competition in almost all areas of business is strong and challenging, and the circumstances of doing business are quickly changing, and digital technologies play a significant role in the business and business operating of organisations from numerous fields. The significance of digital transformations can be seen in the data predicting the market of digital transformations will grow from 150 billion dollars from 2015 to more than 369 billion dollars by the year 2020 [5]. These and other similar statistical data indicate the role of digital transformations in almost all domains of the modern man's functioning.

The formulation and implementation of a digital transformation strategy have become a fundamental concern for numerous organisations which can be characterised as pre-digital, considering the transformational influence of digital technologies on 
almost all aspects of the internal and external organisation of companies and enterprises [6]. It is possible to say that the strategic digital transformation introduces a completely transformed organisational model into the organisation, but, at the same time, it shifts the boundaries of business, while creating transformations in the business processes of an organisation, in which the customers on the one side, and the employees on the other, communicate with algorithms, and not with each other. Considering the numerous demands digital transformation places in front of an organisation, it is clear that the existence of a strategy, primarily a strategy of digital transformation designed and supported by the management of the organisation plays one of the crucial roles in the successful realisation of this process. Numerous studies point out to the role of a strategically conducted digital transformation of an enterprise to different domains of the enterprise's business, such as management processes, business strategies, human resources processes, organisations' business models, product processes, processes of customer/client relationships and similar [7].

One of the especially challenging domains which the companies in our country sometimes strive for when it comes to the digital transformation of organisations, is the complete digital transformation of certain segments of the functioning of an organisation, while other segments of its functioning remain faithful to the previously set patterns of operating. Despite the fact this type of a segmented form of the digital transformation of an organisation can have certain benefits, it is important to understand that business activities organised like that can result in oversights and inadequately applied patterns of digital functioning of enterprises, organisations, and companies. Adequately carried out changes caused by digital technologies within an organisation, and its surroundings demand a transformation of key business processes and encompass all products, processes, as well as organisational structures and management concepts [8].

One of the key elements of a successful strategic digital transformation of an organisation is certainly the existence of a strategy as the system serving to carry out an analysis of the digital transformation processes, determining the order of the steps of the transformation, processes of coordination, and other relevant factors. The key role of the strategy of digital transformation is to harmonise and encompass the different, seemingly independent processes of digital transformation within an organisation [9]. Based on everything adduced it is possible to conclude that the only adequate road towards the realization of the digital transformation of an enterprise is the creation of a clear strategic approach which enables a successful realization of digital transformation in such a manner that it results in qualitative and quantitative changes within the company, its organisation, business, and operating.

Numerous statistical data and the results of studies indicate not only the importance of the digital transformation of organisations but also the importance of a strategic approach to it. Digital transformation has become one of the prime priorities in management systems across the globe, whereas 90 $\%$ of USA's and Great Britain's leaders expect for the digital technologies to become an essential part of the organisation, which impacts the increase of a strategic contribution to their business in this decade [10]. Data indicating the importance of strategic digital transformation among others are the data reported in a study by Galindo-Martin and associates [11], which studied the influence of digital transformation to building company value.

The results of their study, which encompassed all companies which underwent the process of digital transformation within the 29 European countries, indicate the occurrence of a positive cause and effect relationship between the digital transformation of companies, their values, and their entrepreneurial activities. Furthermore, another study showing the importance of digital transformation \& a strategic approach to it is the study conducted by Vial, whose results indicate that $87 \%$ of companies which are a part of the research perceive the strategic digital transformation of a company as a competitive advantage on the market [12]. In a research comprising of 4800 members of different organisations' top management, the results indicate that $76 \%$ of participant consider the existence of a strategy for applying digital technologies in the organisations' business is an important business factor, whereas $92 \%$ of participants feel that this will be an important factor in the next three years [13]. There's another interesting finding, arising from the same study. Namely, $80 \%$ of participants see the digital transformation of an organisation as a chance to succeed, while others see it as a risk for the company's business.

This type and other similar data, as well as the results of different studies, designate the different viewpoints on processes and results of strategic digital transformations of organisations. Despite the fact that the digital transformation of organisations is an extremely demanding and complex process, it is clear that it is also a process which comes with numerous benefits and opportunities for organisations, companies, and enterprises which is why it is important to invest resources, both material as well as human and other into the proper realization of this process.

\section{EXAMPLES OF (UN)SUCCESSFUL STRATEGIC DIGITAL TRANSFORMATION}

Even though we can find a large number of examples of a successful strategic digital transformation of organisations, it is particularly interesting to present the transformations of those organisations whose business has been endangered by the 21st-century modern trends. Namely, the organisations which are especially compromised today are those owning a chain of movie theatres in their business. Considering the digital revolution which is 
highly intensive, aggressive, and constantly increasing the number of users watching movies online, it is natural to ask the question of which methods and techniques should be applied with the goal of survival of numerous movie theatre chains.

This domain portrays the example of a positive strategic digital transformation of an organisation which is suitable for the needs of this paper. Cineplexx movie theatres were founded in 1993, as a part of the Constantin Film Holding company, and today this company's movie theatres are present in Austria, Croatia, Serbia, Slovenia, Montenegro, Macedonia, Albania and Italy with 296 movie auditoriums (41 multiplex and six traditional movie theatres). In 2013 , the company had 1100 employees, 10.5 million visitors, and an income of 115 million euros. The beginning of the digital transformation of this organisation can be linked with introducing digital innovations in the domain of movies screening. In 2009 , the biggest movie theatre chain installed digital equipment for screening movies in all movie theatres. They've replaced tape altogether with movies (content) in a digital form. This significantly simplified and speeded up the process of procurement and delivery of movies and screening materials.

A further strategic approach to the digital transformation of this company and its movie theatre brand is the phase in which they, within their internet presentations or websites, offered their audience an overview of the program, short movie trailers, as well as the processes of movie making and information about the actors. In addition, they introduced the option of online seat reservation and purchasing tickets with the possibility of printing it at your home. They've automated the entrance control using barcodes and barcode scanners and reduced the number of cash registers.

This approach resulted in the forming and constant expansion of the database about the visitors, which created the possibility of reaching out to them directly via internet and digital technologies, as well as the possibility of creating personalized offers, which is one of the most modern approaches to relationships with customers and those using a company's services. Following global trends in the digital development and transformation domain, Constantin Film Holding company introduced the development and application of a mobile app, while simultaneously basing its digital transformation strategy on the increased presence on different social media.

The movie theatre found new partners for delivering digital content, so the clients were offered direct streaming of shows form The Metropolitan Opera, Shakespeare Theater, or The Bolshoi Theater. This drew the attention of a new target group of clients and made room for considering additional content.

To gather the data from the users who didn't sign up over the internet, they offered a club membership and a bonus card where they use various benefits to attain visitors' data to have a better understanding of each visitor's habits and interests. The members of the club can organise their child's birthday party, get a discount on family tickets and have their loyalty rewarded with free tickets. This is just one aspect of the strategic digital transformation of an organisation in a way which can be characterised as successful and adequate for today's business circumstances.

It is hard to single out specific strategic digital transformations which failed, and which could be seen as unsuccessful. Namely, those companies which faced certain losses and troubles during the process of digital transformation have, in most cases, managed to find a way to compensate for the losses and carry out the entire process of digital transformation using appropriate strategies. The "Co-operative Bank" can serve as an example for this type of situation. This is a bank which lost nearly 300 million pounds in the process of digital transformation. The bank started the process of digital transformation in 2006, intending to re-build all its systems to be based on the principles of digital technologies. Although from today's point of view it would be much more appropriate to improve the existing systems and business processes of the bank using digital technologies, the bank decided to completely transform and replace all of its former business principles. The intended digital transformation of the bank was too complex for this company at the given moment. The bank did not have enough human nor material resources to carry out these transformational processes, and in 2013, this newly formed program of the bank's operating was abandoned, due to it being unfunctional. Still, by investing additional efforts, the bank managed to handle the challenges and gradually and systematically carry out the digital transformation of its business processes.

Rather than speaking about complete failures, it is easier to speak about potential risks which can endanger the process of digital transformation. There are numerous different factors which can be considered a risk, among which are primarily inadequate planning, analysis of the needs and the principles on an organisation's operating. Furthermore, inadequate implementation of different segments of the strategic digital transformation of an organisation, which can occur due to numerous reasons, whereas the common lack of resources necessary for successful completion is another potential problem in the process. Often, the process itself is abused by the employers to justify reducing the number of employees, when in essence, the process was not even carried out, so the consequence is a decrease in the number of employees, which is why it has been accepted negatively by the employees from the very beginning [8].

\section{EXAMINING DIFFERENT SEGMENTS OF THE DIGITAL TRANSFORMATION OF ORGANISATIONS}

When it comes to specific research dealing with the examination of the different segments of the digital transformation of organisations, it is possible to say that this is an important research field. In a study 
dealing with examining the factors influencing decision making about the realization of a strategic digital transformation, based on a sample of 1415 companies from 6 European countries, the authors [14] have reached the conclusion that the competing pressure, technological competency, and a tendency towards international business are the factors which immensely influence making a decision about the realization of strategic digital transformation. In accordance with these conclusions are the conclusions of a study conducted by Perry and associates [15]. Namely, these authors point out the significance of strategic digital transformation through the example of the music industry whose members did not immediately decide to go through a digital transformation by using digitalized music, sharing music via the internet and similar, and lost more than 35 percent of value between 2003 and 2012, with total revenues for the period expected to drop from US\$12 billion to $\$ 8$ billion. The conclusion of their study indicates that the members of the music industry who recognised the significance of digital transformation sooner and conducted it strategically, have had a bigger business success than those who did not.

Apart from the research dealing with deciding the realisation of a strategic digital transformation, it is important for the purpose of this paper to mention the research dealing with the prediction of this process. Namely, within their study, Gimpel \& Röglinger [16] recorded the following factors as being in a causeeffect relationship with the success of an enterprise's digital transformation: Customer, Value Proposition, Operations, Data, Organisations, and Transformation Management. Managing these factors is directly related to the success of the realisation of the process of digital transformation, and the authors stand for the use of a self-evaluation instrument which could serve a company's management as a scale for measuring the success of the process of digital transformation in its different phases.

Because the available research and the viewpoints of authors indicate that strategic digital transformation is a demanding, complex, and, for some organisations, an overly difficult task, it is natural to question the status of the realisation of digital transformations in terms of our country's region. Although there are currently no studies dealing with this question in our country, one of the relevant studies from this domain originates from neighbouring Hungary. The sample of the conducted study consisted of more than 100 Hungarian companies, which the author of the research considered to be companies with a critical IT infrastructure. The results of this study shows that $45 \%$ of the companies from the sample do not have a specific strategy for digital transformation, but the digital transformation is a part of a company's global strategy, $10 \%$ of the companies have this type of specific strategy, and $15 \%$ of organisations report to have no plans related to conducting digital transformation [17]. In addition, the authors have applied a 5-point Likert-type scale, based on which the representatives of the organisations evaluated their company's attitudes towards different segments of digital transformation. While they recognised the importance of digital transformation for the company's business success (the average answer was 4.15), they've evaluated their willingness to participate in this process on a significantly lower level (the average answer of 3.36). Based on everything covered in this section of the paper, it is possible to say that the digital transformation of an enterprise, company, or organisation is not just about introducing new or upgrading the old business processes which are based on digital technologies, but there need to be clear, straight-forward, useful, and adequate strategic plans and steps. Numerous indicators point out to the fact that choosing the goal of the digital transformation, an appropriate strategy, and the order of steps to be taken in the process, is a huge challenge for a large number of companies. Estimations say that between $66 \%$ and $84 \%$ of companies do face serious challenges in the process of digital transformation [18]. This statistic should not be discouraging, since considering the complexity of the process of digital transformation, the problems and challenges are a reasonable occurrence. It is important to have adequate resources for successfully overcoming them, both human, material and technological.

\section{CONCLUSION}

Digital transformations will become more and more significant for organisations in the upcoming decade, with the focus on companies' preparation for such changes [19]. Based on everything reported in this paper, it is possible to conclude that one of the most appropriate forms of preparation for the changes happening within an organisation which is keeping up with the time and technology of the modern age, is certainly designing a clear and appropriate strategy of a digital transformation of the organisation. New technologies are transforming the world, redefining customer expectations, enable the business to fulfil customer requirements and changing the way people live and work [20].

This paper aimed to analyse the key elements of the strategic digital transformation of organisations, as well as to analyse cases of organisations which carried out this process successfully, and those who did not achieve the expected goal in the process of digital transformation. As pointed in this paper, numerous factors influence the design of a successful strategy of the digital transformation of organisations on one side and its adequate application on the other. Still, the influence of strategic digital transformation on the business and operating of today's organisations is undisputed. The potential benefits of the strategic digital transformation of organisations are numerous and they include the increase of sales and organisation's productivity, innovations in creating organisation's values, new forms of interaction with clients and customers, whereas the global result is reshaping the entire business model of the organisation 
with the aim of creating a more successful business model [9].

Models of companies which appropriately included the steps and processes of the strategic digital transformation of organisations into their business, such as the Constantin Film Holding company, have been portrayed in this paper, and they indicate the influence of a strategically carried out digital transformation on the business and operating of an organisation.

Despite the fact most enterprises, companies, and organisations have carried out the process of the strategic digital transformation of organisations, it is possible to say that this new approach in the business of companies is still developing and it still has not reached its full capacities. This is why this is becoming an important and relevant subject of research for numerous scientific and practical areas in the years to come, and this subject matter will bring numerous practical implications for the business of the 21 st century.

\section{REFERENCES}

[1] N. Savić, J. Lazarević, Z. Kukić, and E. Marinković, "Digitalna transformacija - izazovi kompanija u Srbiji", Ekonomika preduzeća, vol. 67(1-2), 2019, pp. 101-114.

[2] G. Pitić, G. Radosavljević, M. Babin, and M. Erić, "Digitalizacija poreske administracije u Srbiji", Ekonomika preduzeća, vol. 67(1-2), 2019, pp. 131-145.

[3] R. L. Kliem, "Risk management for business process reengineering projects, , Information Systems Management, vol. 17(4), 2000, pp. 71 .

[4] M. Cortet, T. Rijks, and S. Nijland, "PSD2: The digital transformation accelerator for banks", Journal of Payments Strategy \& Systems, vol. 10(1), 2016, pp. 13-27.

[5] A. M. Sofronijević, V. K. Milićević, and B. J. Ilić, "Strategic approach to digital transformation of business", Tehnika, vol. 72(2), 2017, pp. 273-279.

[6] S. Chanias, M. D. Myers, and T. Hess, "Digital transformation strategy making in pre-digital organisations The case of a financial services provider", The Journal of Strategic Information Systems, vol. 28(1), 2019, pp. 17-33

[7] M. Shahiduzzaman, and K. Marek, "Digital organisation: A value centric model for digital transformation“", 2018.
[8] D. Stojanović, "Digitalna ekonomija i transformacija poslovnih procesa - izazovi i rizici“, Ekonomija: teorija i praksa, vol. 10(1), 2017, pp. 80-90.

[9] C. Matt, T. Hess, and A. Benlian, "Digital transformation strategies", Business \& Information Systems Engineering, vol. 57(5), 2015, pp. 339-343.

[10] T. Hess, C. Matt, A. Benlian, and F. Wiesböck, "Options for formulating a digital transformation strategy", MIS Quarterly Executive, vol. 15(2), 2016, pp.123-139.

[11] M. Á. Galindo-Martín, M. S. Castaño-Martínez, and M. T. Méndez-Picazo, "Digital transformation, digital dividends and entrepreneurship: A quantitative analysis", Journal of Business Research, 2018. https://doi.org/10.1016/j.jbusres.2018.12.014

[12] G. Vial, "Understanding digital transformation: A review and a research agenda", The Journal of Strategic Information Systems, 2019. https://doi.org/10.1016/j.jsis.2019.01.003

[13] G. C. Kane, D. Palmer, A. N. Phillips, D. Kiron, and N. Buckley, "Strategy, not technology, drives digital transformation“, MIT Sloan Management Review and Deloitte University Press, 2015, vol. 14, pp. 1-25.

[14] K. Zhu, S. Dong, S.X. Xu, and K.L. Kraemer, "Innovation diffusion in global contexts: determinants of post-adoption digital transformation of European companies", European journal of information systems, vol. 15(6), 2006, pp. 601-616.

[15] P. Perry, A. Kent, and F. Bonetti, "The use of mobile technologies in physical stores: The case of fashion retailing", In Exploring Omnichannel Retailing, Springer, Cham, 2019, pp. 169-195.

[16] H. Gimpel, and M. Röglinger, "Digital transformation: changes and chances-insights based on an empirical study“, Bayreuth: Fraunhofer Institute for Applied Information Technology FIT, 2015, pp. 1-20.

[17] P. Fehér, Z. Szabó, and K. Varga, "Analysing Digital Transformation among Hungarian Organisations", In Bled eConference, 2017, pp. 40.

[18] B. Libert, M. Beck, and Y. J. Wind, "Questions to ask before your next digital transformation", Harvard Business Review, vol. 60(12), 2016, pp. 11-13.

[19] J. Loonam, S. Eaves, V. Kumar, and G. Parry, "Towards digital transformation: Lessons learned from traditional organisations“, Strategic Change, vol. 27(2), 2018, pp. 101109

[20] V. Obradović, A. Montenegro, and D. Bjelica, "Digital era and project manager's competencies", European Project Management Journal, vol. 8 (1), 2018, pp. 4-9. 